\title{
Flame-Retardant ADP/PEO Solid Polymer Electrolyte for Dendrite-Free and Long-Life Lithium Battery by Generating Al, P-rich SEI Layer
}

Longfei Han, Can Liao, Xiaowei Mu, Na Wu, Zhoumei Xu, Jingwen Wang, Lei Song, Yongchun Kan, * Yuan $\mathrm{Hu} *$

State Key Laboratory of Fire Science,

University of Science and Technology of China

Hefei, Anhui 230026, China

E-mail: yckan@ustc.edu.cn; yuanhu@ustc.edu.cn

Preparation of PEO-Based SPE. PEO $\left(\mathrm{M}_{\mathrm{w}}=6 \times 10^{5}\right.$, Sigma), LiTFSI (Aladdin), and ADP (ZHEJIANG XINHUA CHEMICAL CO., LTD) were dispersed in acetonitrile $\left(\mathrm{CH}_{3} \mathrm{CN}\right.$, AR grade) and they were stirring until the solution becalmed uniform at $25{ }^{\circ} \mathrm{C}$. Transfer the evenly stirred solution to the PVDF mold. The mold was allowed to stand at $25{ }^{\circ} \mathrm{C}$ for $12 \mathrm{~h}$ until most of the solvent evaporates and then transferred to a $60{ }^{\circ} \mathrm{C}$ vacuum oven for $24 \mathrm{~h}$. The SPE was placed in a glove box. To get the $\mathrm{LiFePO}_{4}$ cathode, a slurry method was used. $\mathrm{LiFePO}_{4}$ (LFP) powders were mixed with carbon black and PEO/ LiTFSI $(\mathrm{EO}: \mathrm{Li}=16)$ with a mass ratio of 6:2.5:1.5. Acetonitrile was added as solvent. Next, the slurry was cast on aluminum foil, dried at room temperature, and kept in a vacuum oven at $60^{\circ} \mathrm{C}$ for $12 \mathrm{~h}$ and punched into cathodes. The mass loading of cathode is controlled to be about $1.0 \mathrm{mg} \mathrm{cm}^{-2}$ for this study.

Electrochemical Measurements. In order to test the battery cycle life, 2032-type coin cells were assembled using Li foil as anodes. All assembly process of batteries was carried out in an Ar filled glove box $\left(\mathrm{O}_{2}<0.1 \mathrm{ppm}, \mathrm{H}_{2} \mathrm{O}<0.1 \mathrm{ppm}\right)$. The ionic conductivity of SPE at different temperatures was recorded by sandwiching SPE between two stainless steel (SS) sheets. The result was obtained by AC impedance spectroscopy instrument (Shanghai Chenhua 670 electrochemical workstation) with frequency range from $0.1 \mathrm{MHz}$ to $0.1 \mathrm{~Hz}$ at temperature from 20 to $100{ }^{\circ} \mathrm{C}$. The cells were charged at $0.2 \mathrm{C}\left(1.0 \mathrm{C}=170 \mathrm{~mA} \mathrm{~g}^{-1}\right)$ and $1.0 \mathrm{C}$ from 2.50 to $3.75 \mathrm{~V}$. The alternating current (AC) impedance of cells was conducted using the electrochemical impedance 
spectroscopy (EIS) (Shanghai Chenhua 670 electrochemical workstation) with ac oscillation amplitude of $0.005 \mathrm{~V}$ over the frequency range of $1000 \mathrm{kHz}$ to $0.1 \mathrm{~Hz}$. The electrochemical operating windows were investigated on $60{ }^{\circ} \mathrm{C}$ using linear sweep voltammetry (LSV) test on the coin-type cell of SS/SPE/Li structure. Half cells were normal $\mathrm{LiFePO}_{4} / \mathrm{SPE} / \mathrm{Li}$ cells. Galvanostatic discharge/charge tests were conducted on a Land battery tester (Land CT 2001A, Wuhan, China).

Characterization. Morphology of the ADP nanoparticles and the surface and section of the SPE are observed by a scanning electron microscope (SEM) (Hitachi, Ltd, Tokyo, Japan). Transmission electron microscopy (TEM, JEM-2100F, Japan Electron Optics Laboratory Co., Ltd.) is employed to investigate the micromorphology of ADP nanoparticles and the dispersion of ADP in PEO SPE. This X-ray diffraction (XRD) patterns of the samples was obtain on a XRD (Rigaku Co., Japan) with $\mathrm{Cu} \mathrm{K} \alpha$ radiation $(\lambda=0.15418)$. The Fourier transform infrared (FTIR) spectrum was observed using a Nicolet 6700 spectrometer (Nicolet Instrument Co., USA). The melting point of SPE was carried out on a TA Instruments Q200 differential scanning calorimeter (DSC). X-ray photoelectron spectroscopy (XPS) (V.G. Scientific Ltd., U.K.) was used to gain insight into the chemical configurations using $\mathrm{Al} \mathrm{K} \alpha$ excitation radiation. Thermogravimetric analysis (TGA) was conducted using a Q5000 thermo-analyzer instrument (TA Co., USA) under $\mathrm{N}_{2}$ flow at a heating rate of $20^{\circ} \mathrm{C} \min ^{-1}$. Limiting oxygen index (LOI) test is examined on a limiting oxygen index chamber (Dynisco, Germany) according to ASTM D2863-77. The combustion of SPE is calculated with a microcombustion calorimeter (MCC). 

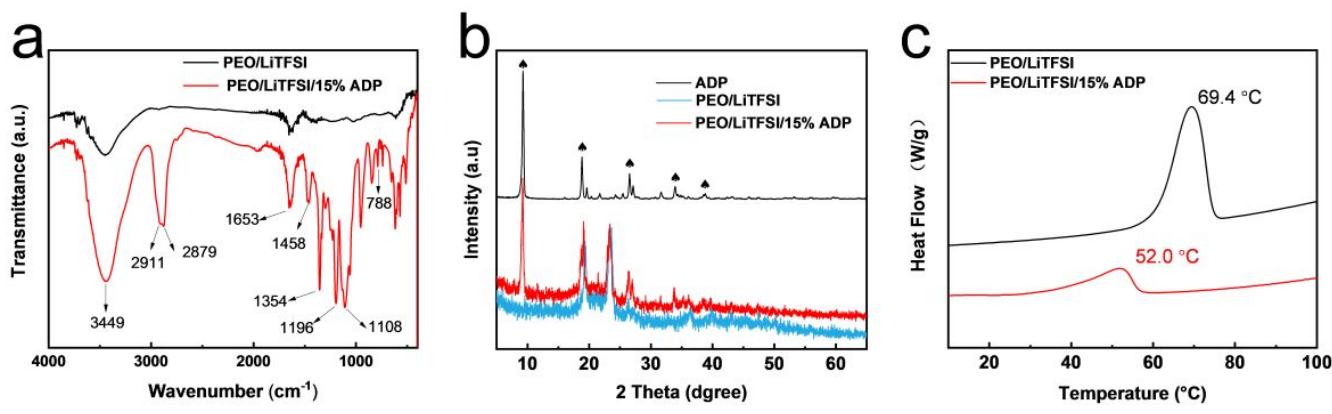

Figure S1. (a) FTIR spectra of PEO/LiTFSI and PEO/LiTFSI/15\%ADP SPE. (b) Typical XRD patterns of ADP, PEO/LiTFSI and PEO/LiTFSI/15\%ADP SPE. (c) DSC curves of the thermal property of PEO/LiTFSI and PEO/LiTFSI/15\%ADP SPE.

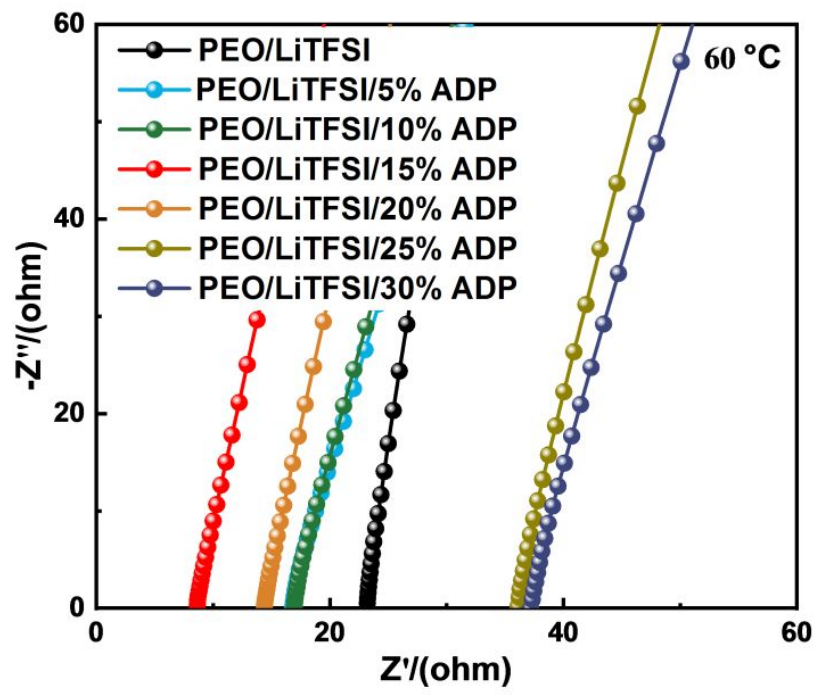

Figure S2. Experimental impedance spectra of various SPE at $60^{\circ} \mathrm{C}$. 


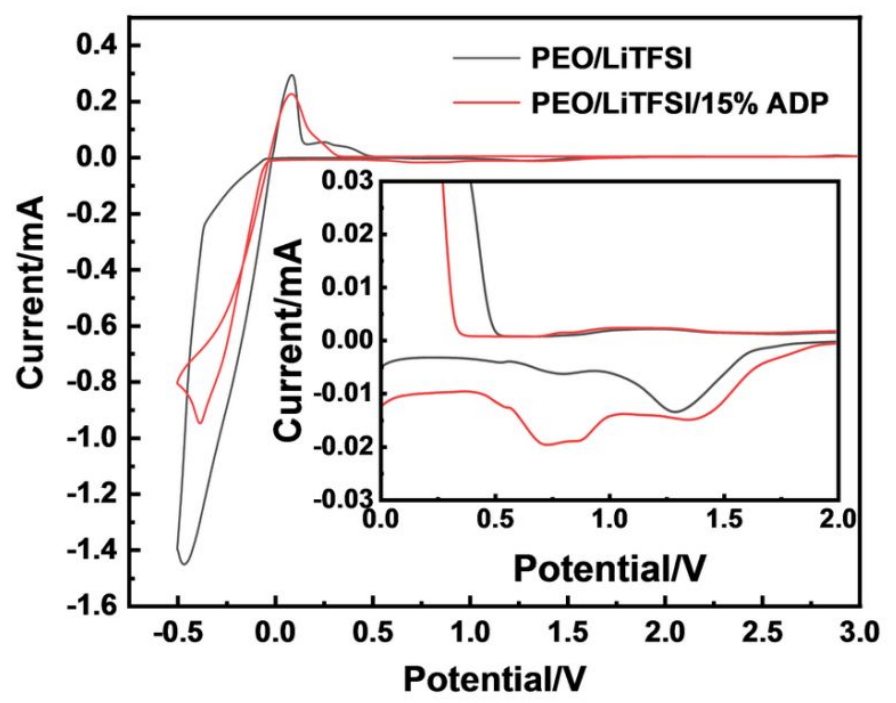

Figure S3. The red line shows the CV curve of a Li/PEO/LiTFSI $/ 15 \%$ ADP/Fe cell from -0.5 to $3.0 \mathrm{~V}$ at $60{ }^{\circ} \mathrm{C}$ and the black line shows the $\mathrm{CV}$ curve of a $\mathrm{Li} /$ $\mathrm{PEO} / \mathrm{LiTFSI} / \mathrm{Fe}$ cell from -0.5 to $3.0 \mathrm{~V}$ with stainless steel as a working electrode.

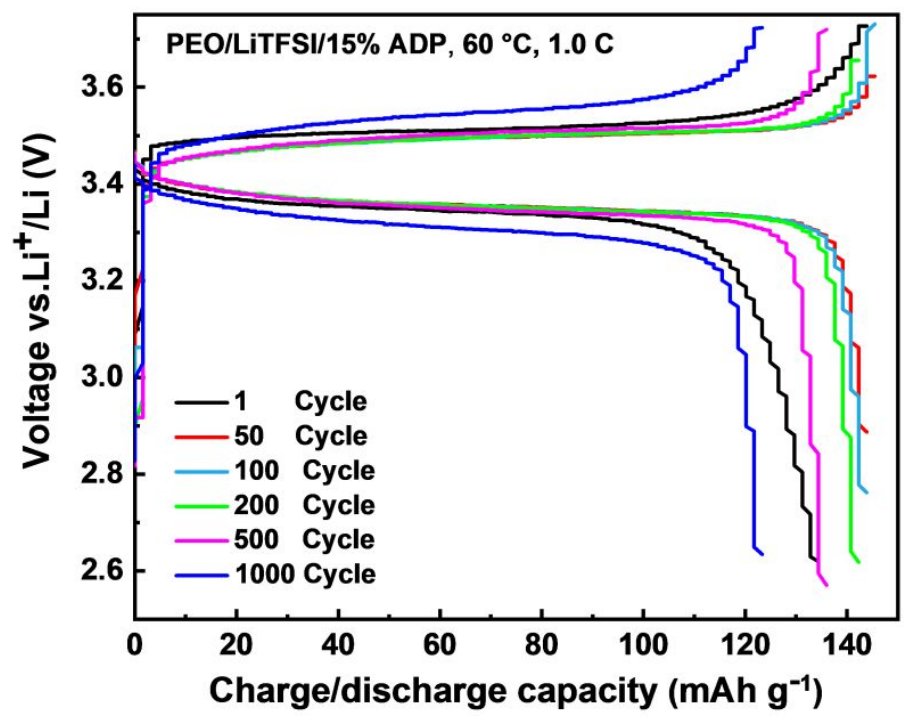

Figure S4. Charge-discharge curves versus cycle number of $\mathrm{LiFePO}_{4} / \mathrm{PEO} / \mathrm{LiTFSI} / 15 \% \mathrm{ADP} / \mathrm{Li}$ cell under a voltage range of $2.8-3.75 \mathrm{~V}$ versus $\mathrm{Li} / \mathrm{Li}^{+}$. 


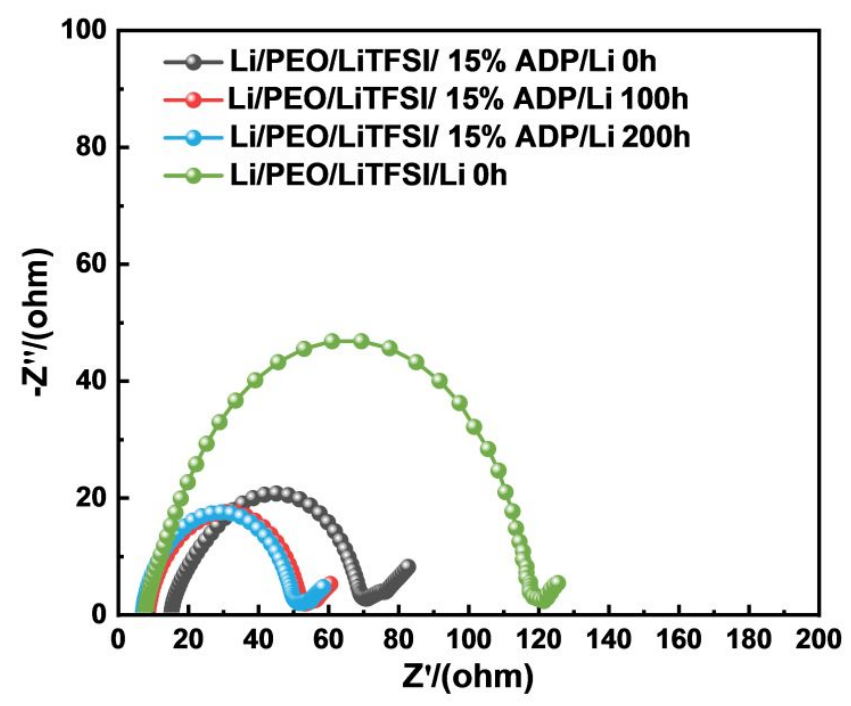

Figure S5. IMP plots of the symmetric cells at $60^{\circ} \mathrm{C}$.

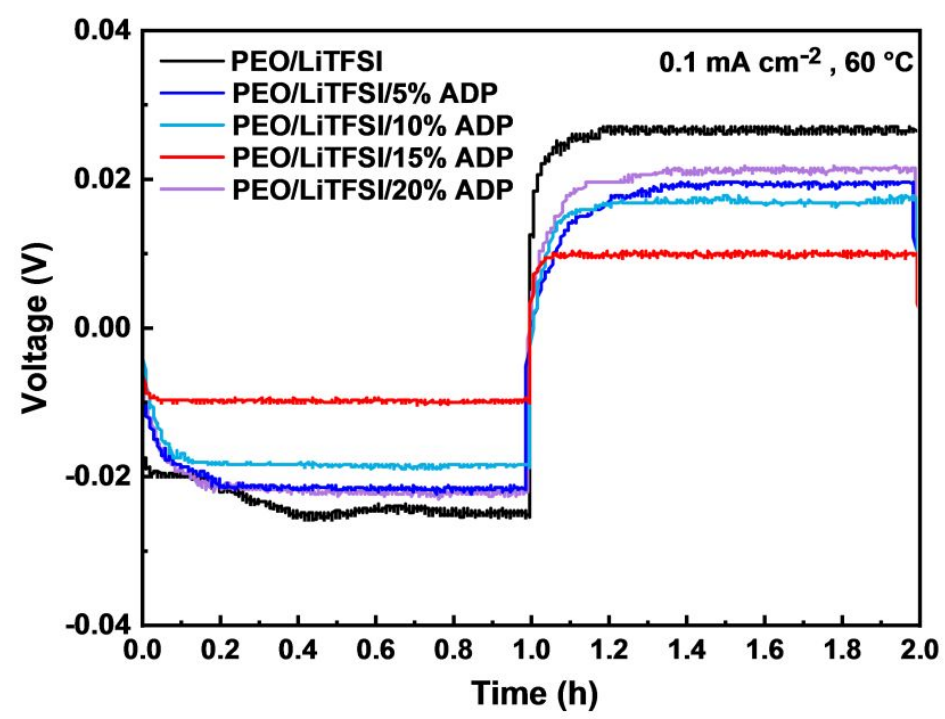

Figure S6. The magnified plating/stripping cycles of various SPE. 
$\mathbf{a}$
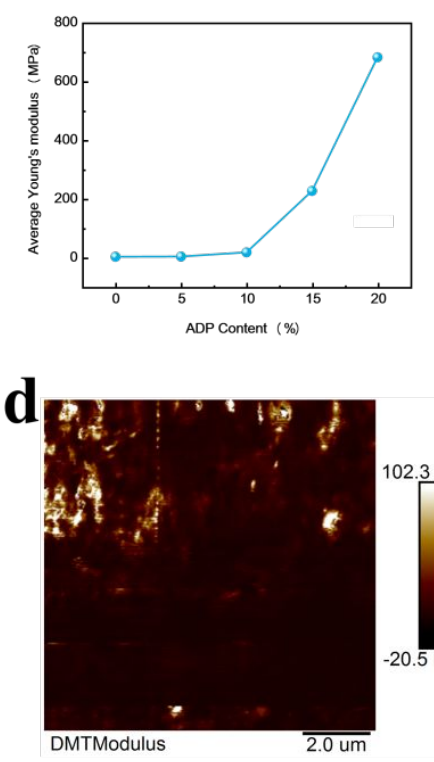

b
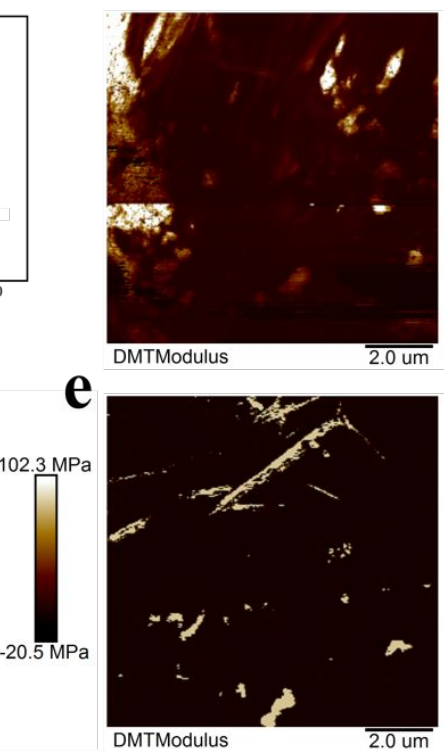

c

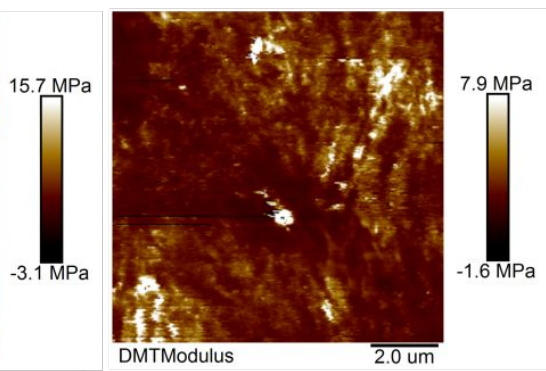

f

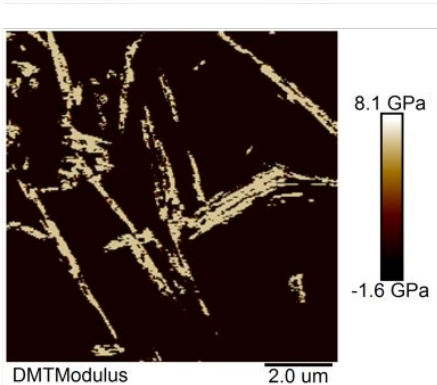

Figure S7. (a) Average Young's Modulus of SPE and content of different Flame retardants. Young's modulus mapping figure of the (b) PEO/LiTFSI, (c) PEO/LiTFSI/5\% ADP, (d) PEO/LiTFSI/10\% ADP, (e) PEO/LiTFSI/15\% ADP, and (f) PEO/LiTFSI/20\% ADP.
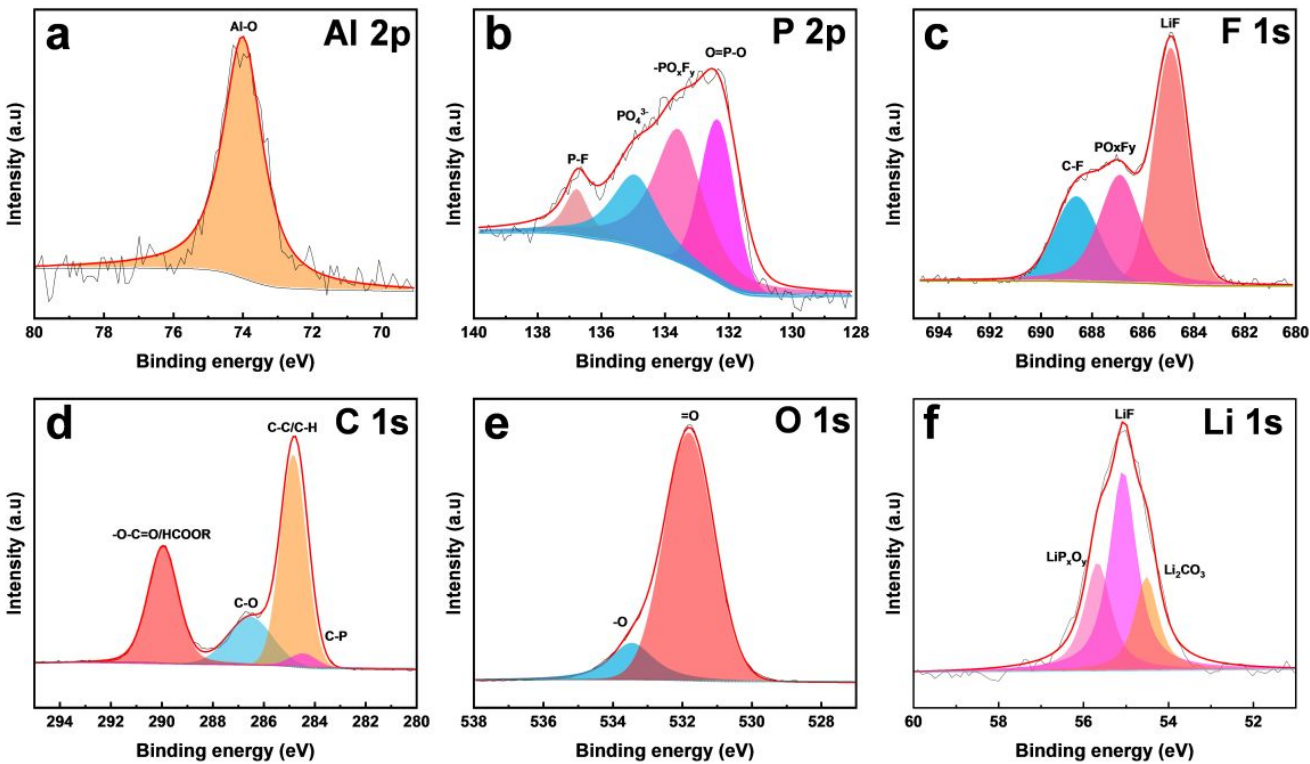

Figure S8. XPS analyses for (a) Al 2p, (b) P 2p, (c) F 1s, (d) C 1s, (e) O 1s and (f) Li 1s 
performed on cycled Li electrode for Li/SPE/Li battery after $200 \mathrm{~h}$.

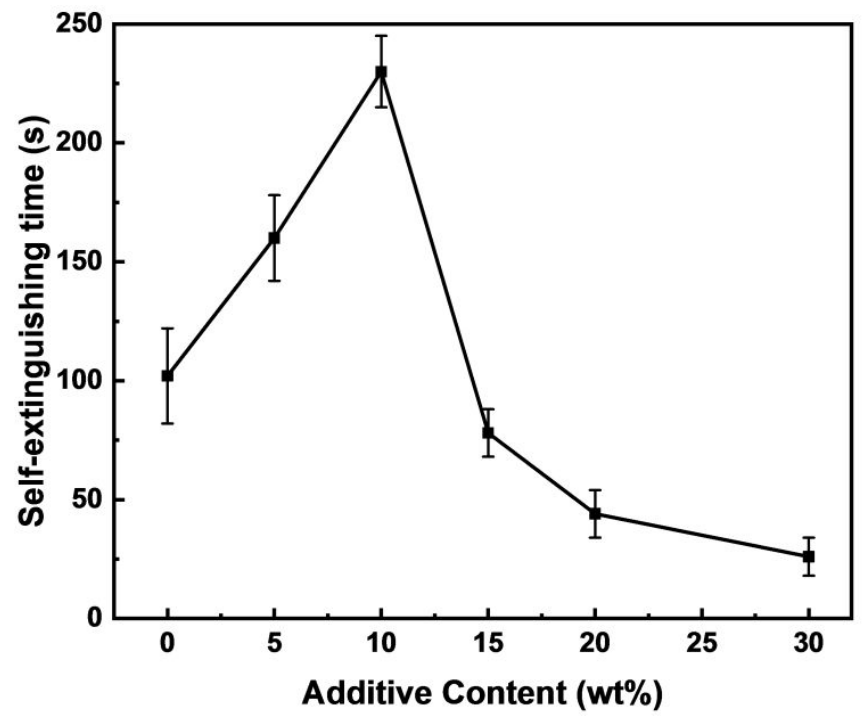

Figure S9. Self-extinguishing time test of PEO and flame retardant with different concentration.

a
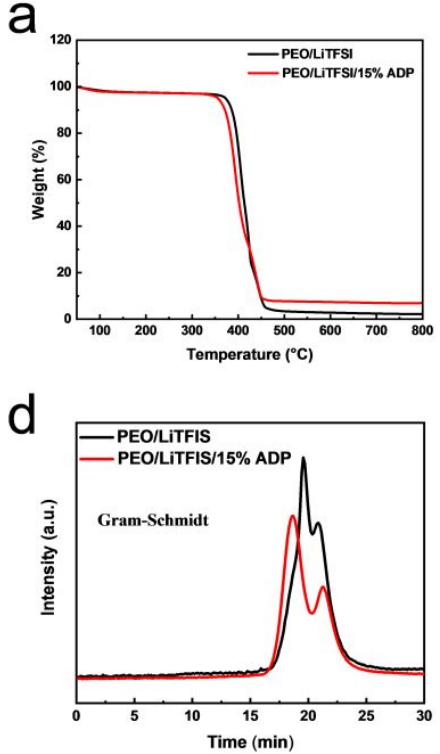

b

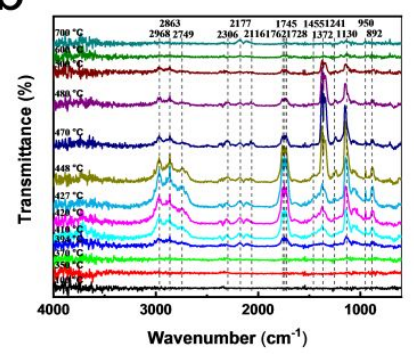

e

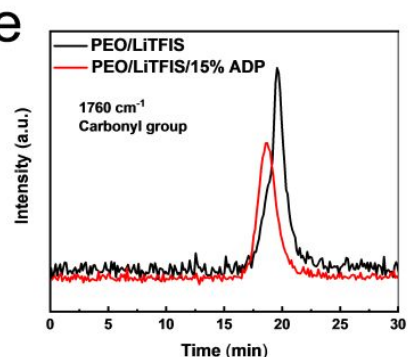

C

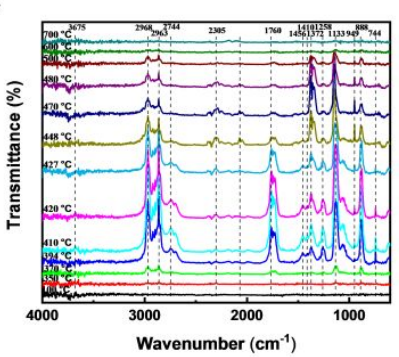

f

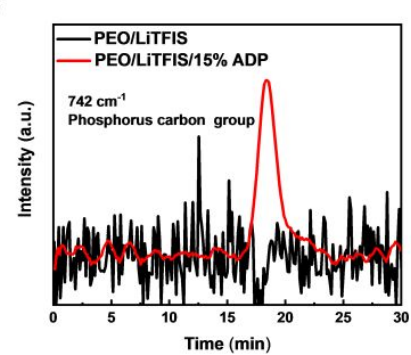

Figure S10. (a) TGA curves of PEO/LiTFSI and PEO/LiTFSI/15\% ADP in TG-FTIR test. FT-IR spectra of (b) PEO/LiTFSI and (c) PEO/LiTFSI/15\% ADP at different pyrolysis temperatures. Absorbance of pyrolysis products versus time curves of PEO/LiTFSI and PEO/LiTFSI/15\% ADP: (d) total pyrolysis products, (e) carbonyl group and (f) Phosphorus carbon group, respectively. 


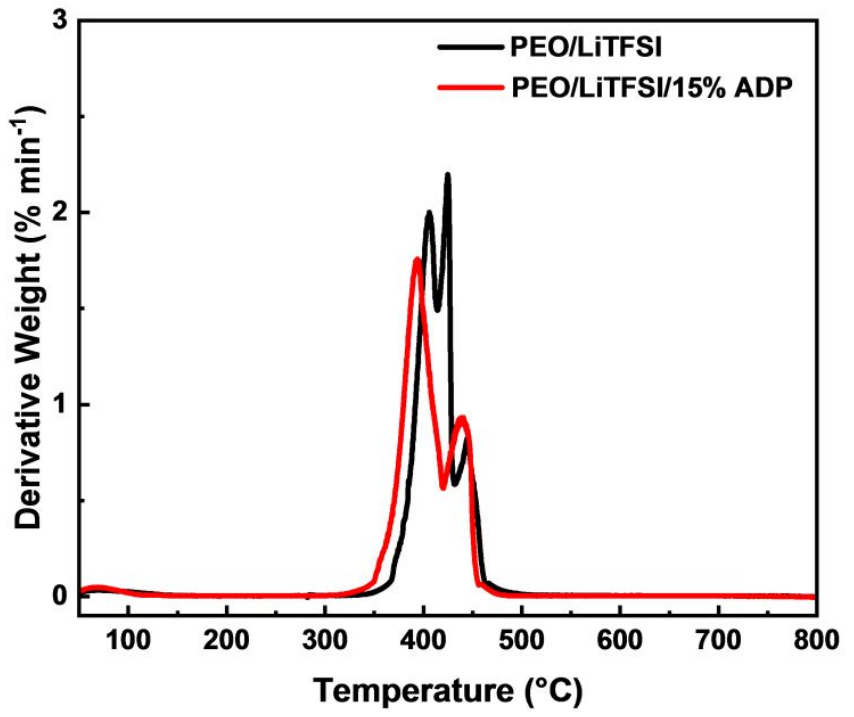

Figure S11. DTG curves of PEO/LiTFSI and PEO/LiTFSI/15\% ADP in TG-FTIR test. 